\title{
The effect of vegetable oil combination and surfactant PEG 7 glyceryl cocoate ratio on physical characteristics and physical stability of arbutin microemulsion
}

\author{
Yuli Ainun NAJIH, Dita Nurlita RAHMA, Yuyun NAILUFA, Rachmah Dwi PRASETYOWATI \\ Study program of S1 Pharmacy, Faculty of Health, University of Hang Tuah, Surabaya, Indonesia
}

\begin{abstract}
Alpha arbutin is the anti hyper-pigmentation works as tyrosinase inhibitors. Arbutin is hydrophile needs the development formula to improve the penetration into skin is microemulsion. The purpose of this study is to determine ratio of combined vegetable oils and surfactants on to availability microemulsions alpha arbutin. This research begins with the optimization of microemulsion bases that used of sunflower oil, VCO, grape seed oil, almond oil as oil phase (1:1), PEG 7 glyceryl cocoate as surfactant used spontaneous emulsification method. It obtained 3 great formulas with ratio of oil:surfactant F3 (10:65), F4 (15:70), and F5 (7:80). The droplet size results that obtained in a consecutive is $0.013 \mu \mathrm{m}$; $0.027 \mu \mathrm{m} ; 0.050 \mu \mathrm{m}$, polydispersion index consecutive is $0.134 ; 0.216 ; 0.602$, with the consecutive of the zeta potential is $-24.83 \mathrm{mV} ;-24.66 \mathrm{mV} ;-27.30 \mathrm{mV}$. It continues the evaluation includes $\mathrm{pH}$, specific gravity, viscosity, centrifugation, and cycling test. It obtained the significant differences to the droplet size with the consecutive value is $0.013 \mu \mathrm{m} ; 0.023 \mu \mathrm{m}$; $0.027 \mu \mathrm{m}$, consecutive polydispersion index is $0.119 ; 0.191 ; 0.276$, the consecutive zeta potential is $-2.79 \mathrm{mV} ; 1.06 \mathrm{mV}$; $-3.10 \mathrm{mV}$, consecutive $\mathrm{pH}$ value is $5.18 ; 5.21 ; 5.25$, and consecutive viscosity is $150.3 \mathrm{cps} ; 161.6 \mathrm{cps} ; 196.3 \mathrm{cps}$. The result that obtained shows that microemulsion preparations are not stable during the storage process.
\end{abstract}

Keywords: alpha arbutin, microemulsion, PEG 7 glyceryl cocoate, characteristic of microemulsion, stability of microemulsion

\section{INTRODUCTION}

The UV light stimulation from sun actually has the benefits as forming vitamin D3 which acts as bone formation and immune system [1]. But continuous exposure will cause the pigmentation problem because excessive melanin production (hyperpigmentation) causes dark patches on the skin.
Arbutin is derivative of

hydroquinone which works as a lightening skin with inhibits the tyrosinase enzyme, where the enzyme which acts as in melanin synthesis [2]. The benefit of arbutin is safer, less toxic, and more effective than hydroquinone [3]. Alpha arbutin shows the tyrosine suppression activity stronger than $\beta$-arbutin in rat malignant melanoma cells $[4,5]$. The nature of physicochemistry from arbutin is hydrophile cause problems in the penetration of lipophilicity corneal stratum while the target arbutin work is stratum germinativum layer which is located at the very bottom of the epidermis layer which is hydrophile, so it is necessary to 
develop the dosage forms that can increase the penetration of arbutin [6].

Microemulsion is the preparation form innovations that can be used to improve the efficiency in penetration from skin compared to conventional dosage forms [7]. The method makes microemulsion is the development method from emulsion [8]. The nature of thermodynamic microemulsion can support partitioning into the skin [7]. The droplet size of microemulsion is around $10-100$ $\mathrm{nm}[9,10]$. Microemulsion composed of oil and water which is stabilized with a surfactant molecular film interface and usually with co-surfactants [11]. The oil phase that is utilized can come from nature which contains of antioxidants, anti-inflammatory, and other activity which can support skin repair due to free radicals. The surfactant concentration or co-surfactants which used in the formation of microemulsion ranges $20-80 \%$ $[12,13]$. PEG 7 glyceryl cocoate is non-ionic surfactant with the value of HLB 11 which has benefits as emulsifying and emollient, usually used as surfactant in hair treatment and skin care products and safe to use up to $100 \%$ concentration [14].

The ratio of oil surfactant and the type of oil used can influence the stability of colloidal dispersion [15]. There are the differences of oil concentration and surfactant can give the influenced on transparency (\% transmitan), turbidity (\% turbidity) and viscosity from system of microemulsion dosage with the kind of oil that used will influenced on microemulsion droplet particle diameter produced [16]. In this research is implemented the making microemulsion preparations with various ratios of vegetable oil and surfactants to see the effect on physical characteristics and physical stability of arbutin microemulsions.

\section{MATERIALS AND METHODS}

The research is implemented in Pharmacy Technology Laboratory Study Program Faculty of Medicine, Hang Tuah University, Surabaya and Material Physics Laboratory, Faculty of Mathematics and Natural Sciences, Sepuluh November Institute of Technology from October 2019 to November 2019. The type of research method is the experimental with formula optimization method. The active ingredient is used in this research is alpha arbutin. Variable independent in this research is ratio of ratio of combined vegetable oils and surfactants. Variable dependent is physical quality parameters of the emulgel include organoleptic, emulsion type, droplet size, polydispersity index, zeta potential, $\mathrm{pH}$, specific gravity, viscosity, and centrifugation test. While controlled variable is in the form of magnetic stirrer speed and temperature.

\section{Tools and material}

Tools that used in this research is analytical scales, Beaker glass, Measuring cups, stirring rods, porcelain cups, horn spoons, tweezers, magnetic stirrer, Hotplate, $\mathrm{pH}$ meter Horiba Scientific, Piknometer Gay-Lussac, HEALTH centrifuge 8 HOLE timer, oven. While the material that used in this research there are Alpha Arbutin (manufactured by Shandong Topscience Biotech Co., Ltd. From China), Sunflower oil is produced by Ykpaina / Ukraine, Virgin Coconut Oil (VCO) (produced by Natures, Indonesia), Grape Seed 
Oil (produced by New Directions Aromatics, USA and Canada), Almond Oil (produced by New Directions Aromatics, USA and Canada), PEG 7 glyceryl Cocoate (produced by Solvay, Beligum), Methylene blue (produced by PT. Anugerah Jaya, Indonesia), Aquadest (produced by Brataco, Indonesia).

\section{Procedure}

This research is conducted with several stages which is implemented optimization with several formulas. Making arbutin microemulsion formulations implemented with the how to dissolve the active ingredient into aquadest and mix it into PEG 7 glyceryl cocoate with mixing the oil phase over the watebath with using thermometer to control the temperature $30^{\circ} \mathrm{C}$. Then mixing the water phase into oil phase which has been put into a glass beaker on the hotplate and stirring at $560 \mathrm{rpm}$ \pm 5 minutes at $30^{\circ} \mathrm{C}$. Then, from the result it can obtain will choose the greatest formulas based on the formed pseudoternary phase diagram. Then it chooses again the selected formula based on the droplet size, polydispersity index, zeta potential which fulfilling that meets micro-emulsion requirements. Micro-emulsion dosage then implemented characteristic test and physical stability. There are the tested parameter including organoleptic test, emulsion type, droplet size, polydispersityindex, zeta potential, $\mathrm{pH}$, specific gravity, and viscosity. While for physical stability test includes centrifugation test preparation.

Cycling test stability test is the microemulsion preparation was stored at $4^{\circ} \mathrm{C}$ for 24 hours, and then the preparation was transferred at $40^{\circ} \mathrm{C}$ for 24 hours ( 1 cycle). The test was carried out in 6 cycles (12 days) and a comparison of the observations before and after the test was made

Examination of the droplet size distribution, polydispersity index and zeta potential of microemulsions was carried out using the Malvern Zetasizer Particle Size Analyzer. The microemulsion sample was shaken to homogenize the liquid. Then the cuvette was inserted and observations were made at an angle of $175^{\circ}$ for the droplet size and polydispersity index and 12.8 for the zeta potential at a temperature of $25^{\circ} \mathrm{C}$ [17].

$\mathrm{PH}$ measurements are carried out using a $\mathrm{pH}$ meter which is calibrated first using a basic solution of $\mathrm{pH} 4.00$ and 7.00 before measuring the microemulsion $\mathrm{pH}$ $[18,19]$. Then the electrodes are washed with distilled water, and then dried with a tissue. The microemulsion preparation is poured into a beaker glass, and then the electrode on the $\mathrm{pH}$ meter is immersed into the microemulsion preparation until the $\mathrm{pH}$ meter shows a stable number.

Density test using pycnometer by weighing the empty pycnometer on the analytical balance first. Then fill the pycnometer with the preparation until it is full and then weigh it with analytical scales. Viscosity is a property that determines resistance to shear forces. The microemulsion flow shows a non-newtonian flow [20]. Microemulsion viscosity measurement can be done using a Brookfield viscosimeter [21]. 
TABLE 1. Microemulsion formulation design

\begin{tabular}{|c|c|c|c|}
\hline Formula & $\begin{array}{c}\text { Oil } \\
\text { phase }\end{array}$ & Surfactant & $\begin{array}{c}\text { Water } \\
\text { based }\end{array}$ \\
\hline 1. & 2 & 35 & 63 \\
\hline 2. & 4 & 40 & 56 \\
\hline 3. & 6 & 45 & 49 \\
\hline 4. & 10 & 65 & 25 \\
\hline 5. & 15 & 70 & 15 \\
\hline 6. & 20 & 60 & 20 \\
\hline 7. & 20 & 13 & 67 \\
\hline 8. & 25 & 55 & 20 \\
\hline 9. & 30 & 60 & 10 \\
\hline 10. & 35 & 55 & 10 \\
\hline 11. & 2 & 85 & 13 \\
\hline 12. & 7 & 80 & 13 \\
\hline
\end{tabular}

RESULTS AND DISCUSSION

Diagram pseudoternary used to determine the concentration percentage from each component in making the system of microemulsion. In the tables 2, 3, 4 is the introduction formulation result to determine and to know to determine the point of formation of the microemulsion system.

Based on the statistical results in Table 2 used Kruskal Wallis, the significance value is $p<0.05$, which means that there is a significant difference in droplet size. The results of the polydispersity index statistical analysis from Table 3 using two-way ANOVA obtained a significance value of $p<0.05$, where there were significant differences in each formula. The determination of the 3 selected formulas apart from seeing the results of the droplet size and polydispersity index also considers the particle charge of a preparation indicated by the zeta potential results in Table 4 then analyzed using two-way ANOVA obtained a significance value of $p<0.05$ where there are significant differences in each formula. This difference occurs between F1 and F2 where there are differences with $\mathrm{F} 3, \mathrm{~F} 4$, and F5. Based on these results, the 3 best formulas were selected, namely F3, F4, F5 by considering the potential zeta value that is closest to the requirements.

Based on the tables 2, 3, 4 and figure 1 the concentration percentage of microemulsion component which can form microemulsions with a clear appearance and transparency is formula with a ratio of oil:surfactant:water respectively F1 (2:35:63); F2 (4:40:56); F3 (6:45:49); F4 (10:65:25); F5 (15:70:15); F11 (2:85:13); and F12 (7:80:13). Instability of microemulsion system occurs to F6 (20:60:20), F8 (25:55:20), F9 (30:60:10), F10 (35:55:10) the system turns turbid. Point 7 or F7 (20:13:67) system does not form microemulsions, but it turns emulsion that shows with the milky white appearance and not transparent.

The optimization results of several formulas based on the diagram of pseudoternary phase obtained 5 greatest formulas which is F1 (4:40:56), F2 (6:45:49), F3 (10:65:25), F4 (15:70:15), F5 (7:80:13). Then formula is chosen based on the droplet size, polydispersity index, and zeta potential that meets the requirements of microemulsion there are F3, F4 and F5 droplet size value of each is $0,013 \mu \mathrm{m}, 0,027 \mu \mathrm{m}$, and $0,050 \mu \mathrm{m}$; polydispersity index value of each is 0,$134 ; 0,216$; and 0,602 ; with zeta potential value of each is 24,$83 ;-24,7$; and $-27,3$. In the result has obtained data is increasing the use of surfactant so it is bigger the droplet size. The more adding surfactant so surfactant will leaves in the liquid and the molecule will bigger $[22,23]$. 
TABLE 2. Evaluate droplet size

\begin{tabular}{|c|c|c|c|c|c|}
\hline \multirow{2}{*}{ Replication } & \multicolumn{5}{|c|}{ Formula } \\
\cline { 2 - 6 } & F1 (4:40:56) & F2 (6:45:49) & F3 (10:65:25) & F4 (15:70:15) & F5 (7:80:13) \\
\hline 1 & $12.51 \mathrm{~nm}$ & $12.37 \mathrm{~nm}$ & $13.16 \mathrm{~nm}$ & $27.13 \mathrm{~nm}$ & $56.97 \mathrm{~nm}$ \\
\hline 2 & $12.44 \mathrm{~nm}$ & $12.29 \mathrm{~nm}$ & $13.10 \mathrm{~nm}$ & $27.96 \mathrm{~nm}$ & $51.33 \mathrm{~nm}$ \\
\hline 3 & $12.47 \mathrm{~nm}$ & $12.30 \mathrm{~nm}$ & $13.06 \mathrm{~nm}$ & $28.53 \mathrm{~nm}$ & $43.90 \mathrm{~nm}$ \\
\hline Average $\pm S D$ & $12.47 \pm 0.03$ & $12.32 \pm 0.04$ & $13.11 \pm 0.05$ & $27.88 \pm 0.70$ & $50.73 \pm 6.55$ \\
\hline$=$ & $0.012 \mu \mathrm{m}$ & $0.012 \mu \mathrm{m}$ & $0.013 \mu \mathrm{m}$ & $0.027 \mu \mathrm{m}$ & $0.050 \mu \mathrm{m}$ \\
\hline
\end{tabular}

TABLE 3. Polydispersity index evaluation

\begin{tabular}{|c|c|c|c|c|c|}
\hline \multirow{2}{*}{ Replication } & \multicolumn{5}{|c|}{ Formula } \\
\cline { 2 - 6 } & F1 (4:40:56) & F2 (6:45:49) & F3 (10:65:25) & F4 (15:70:15) & F5 (7:80:13) \\
\hline 1 & 0.215 & 0.045 & 0.151 & 0.228 & 0.636 \\
\hline 2 & 0.209 & 0.044 & 0.136 & 0.211 & 0.588 \\
\hline 3 & 0.169 & 0.020 & 0.116 & 0.210 & 0.583 \\
\hline Average $\pm S D$ & $0.197 \pm 0.025$ & $0.036 \pm 0.014$ & $0.134 \pm 0.017$ & $0.216 \pm 0.01$ & $0.602 \pm 0.03$ \\
\hline
\end{tabular}

TABLE 4. Zeta potential evaluation

\begin{tabular}{|c|c|c|c|c|c|}
\hline \multirow{2}{*}{ Replication } & \multicolumn{5}{|c|}{ Formula } \\
\cline { 2 - 6 } & F1 (4:40:56) & F2 (6:45:49) & F3 (10:65:25) & F4 (15:70:15) & F5 (7:80:13) \\
\hline 1 & -11.8 & -6.59 & -19.4 & -27.0 & -13.0 \\
\hline 2 & -10.2 & -10.6 & -28.9 & -20.5 & -29.0 \\
\hline 3 & -11.0 & -10.1 & -26.2 & -26.5 & -39.9 \\
\hline Average $\pm S D$ & $-11 \pm 0.8$ & $-9.1 \pm 2.18$ & $-24.83 \pm 4.89$ & $-24.7 \pm 3.61$ & $-27.3 \pm 13.53$ \\
\hline
\end{tabular}

Surfaktan (\%)

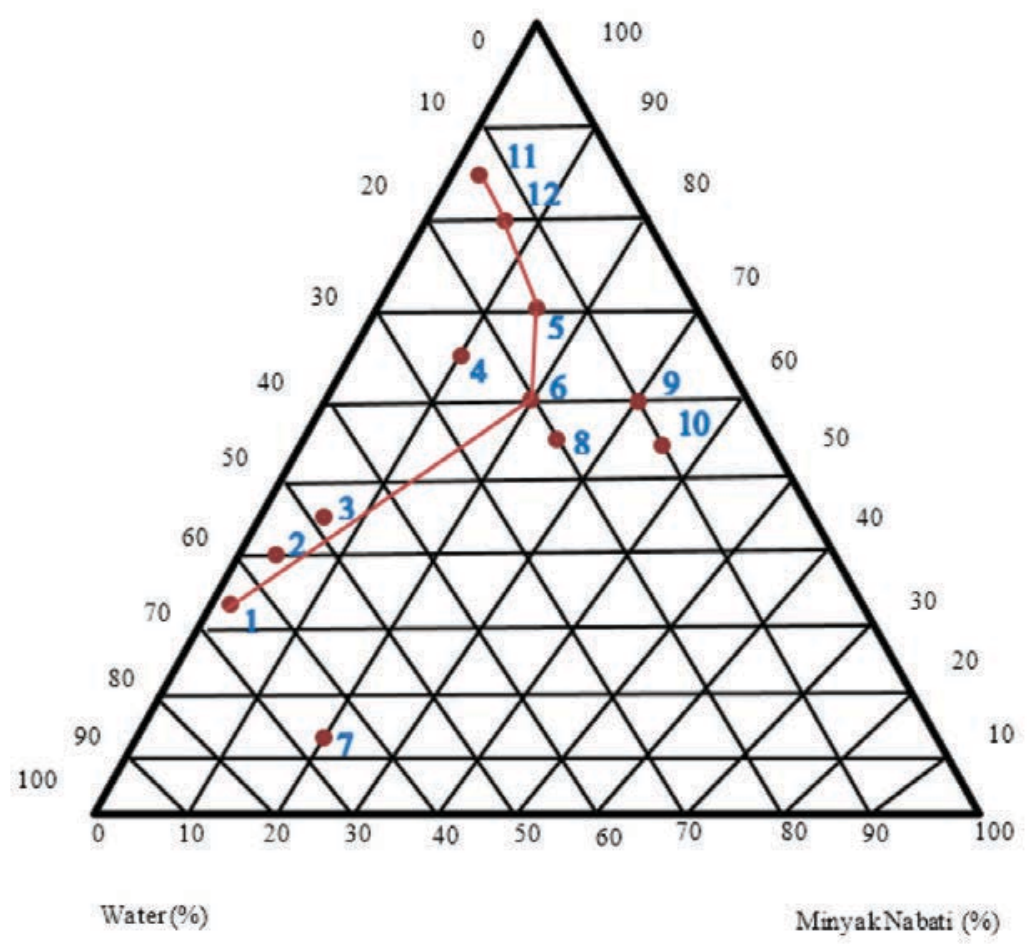

FIGURE 1. Pseudoternary Diagram of Microemulsion Formulation

The comparison of the results of the droplet size before and after the cycling test can be seen in
Figure 2. The result of droplet size after conducting cycling test decreased F4 and F5, each is 0.023 


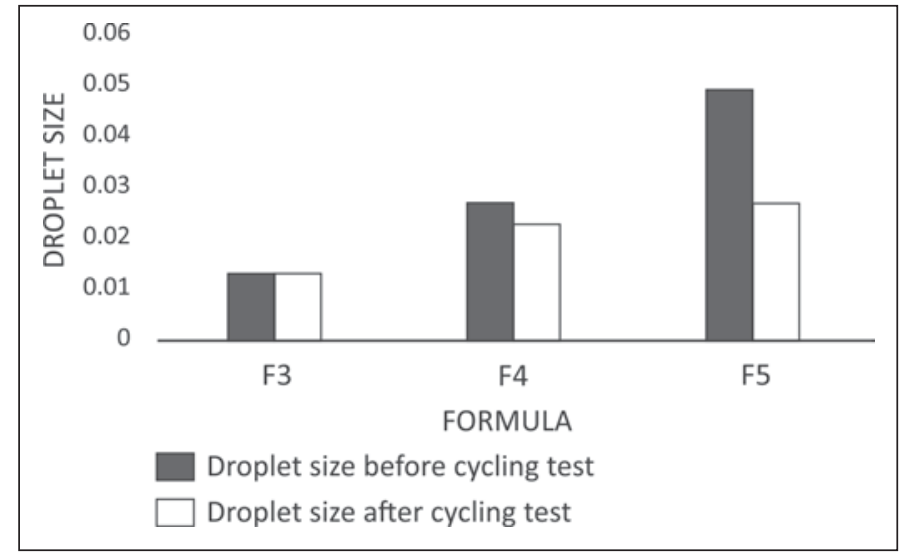

FIGURE 2. Histogram Size of Microemulsion Droplets Type 0 / $W$ F3, F4, and F5

$\mu \mathrm{m}$ and $0.027 \mu \mathrm{m}$. cycling test implemented during 12 days ( 6 cycles) in the temperature each at $4^{\circ} \mathrm{C}$ and $40^{\circ} \mathrm{C}$ respectively for 24 hours. There are the changes can caused because there are the use of non-ionic surfactant, where the hydrogen relation between water molecules with hydrophilic groups from surfactants will be destructed with increasing temperature [24].

Polydispersity index value shows that all formulas including monodisperse type (particles of uniform size) where the PDI value for nanoparticle is 0.05-0.7 Yenilmez (2017). The smaller polydispersity index value so the particle distribution in a component has the level of uniform size [26].
The differences of zeta potential value before and after from cycling test can be seen in the histogram figure 3. The zeta potential result of all formulas does not meet the expected range of $\leq-30 \mathrm{mV}$ or $\geq+30 \mathrm{mV}$ [27]. Zeta potential stated that the differences the potential between disperse media and the stationary fluid layer attached to dispersed particles [28]. Although it occur the improvement after cycling test, zeta potential value is still does not meet the expected of zeta potential requirement in stable micro-emulsion preparations. This is shows unstable preparation.

The organoleptic examination results of the three formulas are based on figure 4 obtained physical

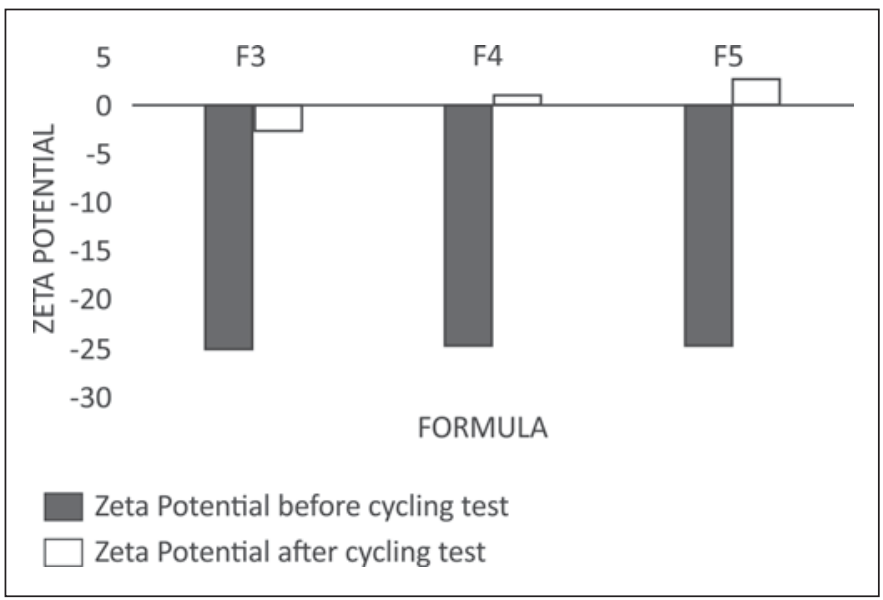

FIGURE 3. Zeta Histogram Potential Microemulsion Type O / W F3, $F 4$, and $F 5$ 


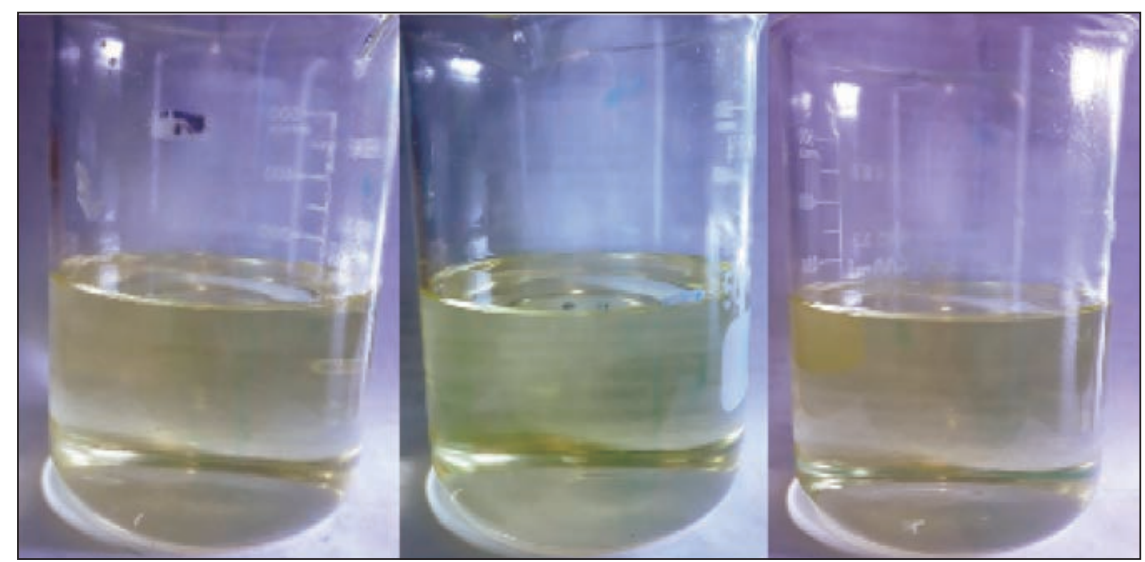

FIGURE 4. Physical appearance of Microemulsion F3, F4 and F5

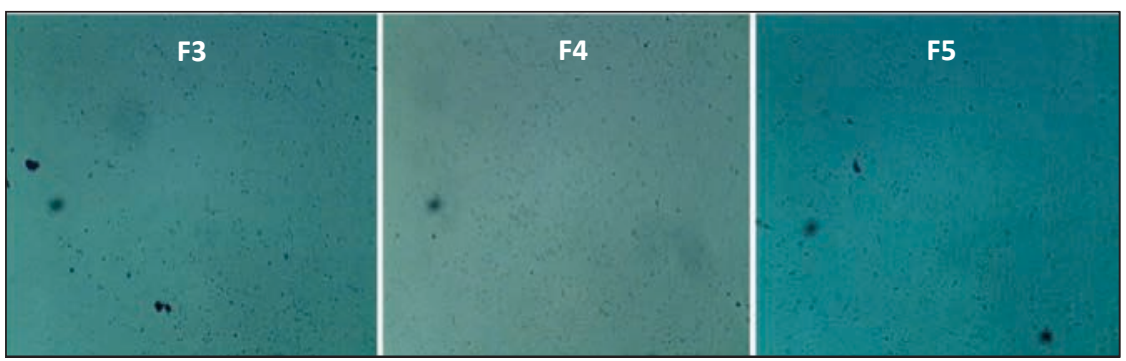

FIGURE 5. Physical appearance of Microemulsion F3, F4 and F5

appearance in the form of a characteristic odor, pale yellow color, clear and 1 phase.

The emulsion type that obtained shows in the figure 5 with adding methylene blue shows microemulsion with the type of Oil in Water $(\mathrm{O} / \mathrm{W})$. There is adding methylene blue which is watersoluble dyes cause the blue color to spread evenly on the preparation [29].
The $\mathrm{pH}$ test results obtain $\mathrm{pH}$ preparation before cycling test between other 5.14;5.19; and 5.20, after cycling test occurs the improvement of 5-6. Range of skin $\mathrm{pH}$ is 4.5-6.5 and $\mathrm{pH}$ alpha arbutin stability is 3.5-6.5 [30]. There are found the differences meaning for each formula caused by differences in the percentage of water in each formula until the needs citrate buffer $\mathrm{pH} 3.5$ that used also

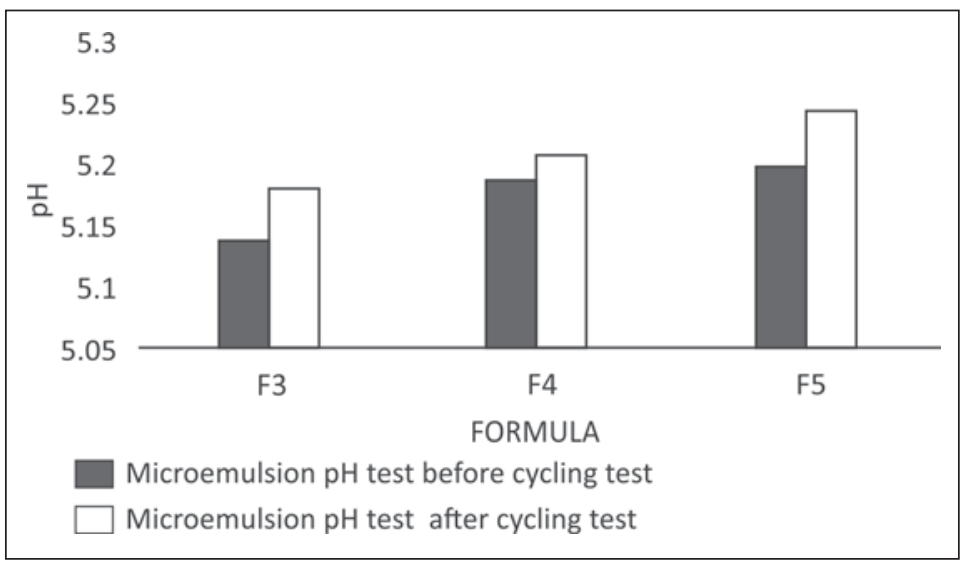

FIGURE 6. Histogram pH Microemulsion Type O / W F3, F4, and F5 
different. Except using citrate buffer to buffer the $\mathrm{pH}$ value in this research also needs adding HCL 0.1 $\mathrm{N}$ to help decrease $\mathrm{pH}$ value preparation. There adding HCL 0.1 $\mathrm{N}$ this is cause because citrate buffer $\mathrm{pH} 3.5$ is not able to decrease $\mathrm{pH}$ preparation because the biggest percentage surfactant PEG 7 glyceryl cocoate that used have the value of $\mathrm{pH}$ is 7 . Inability to citrate buffer $\mathrm{pH} 35$ and HCL 0.1 $\mathrm{N}$ in maintaining the $\mathrm{pH}$ value is also showed in the result after cycling test where $\mathrm{pH}$ in all formulas conduce the improvement.

In the specific gravity test results, all formulas are not found the difference meaning whether before or after implementing cycling test. It obtained the specific gravity data in each of the formula is 1.0432; 1.0369; 1.0425; and data after cycling test each of $1.0371 ; 1.0296$; and 1.0464 .
It obtained the viscosity analysis result of each formulas is $149.6 \mathrm{cps}$; $163.3 \mathrm{cps}$; dan $181.3 \mathrm{cps}$. The viscosity test is implemented with using viscometer Brookfield with the speed of $30 \mathrm{rpm}$ in the room temperature. The viscosity assessment results showed the differences meaning in each formula. From the viscosity value is obtain showed many more surfactant concentration which adding so the viscosity become increase. This occur the presence of excess surfactants causes' concentration critical micelle concentration $(\mathrm{CMC})$ decrease that cause aggregate or micelles that formed become more, not symmetrical and bind to each other that caused viscosity preparation become increase [31,32]. The viscosity value after implemented cycling test occur the improvement in F3 and F5 is 150.3 cps and 196.3 cps. This might caused because the

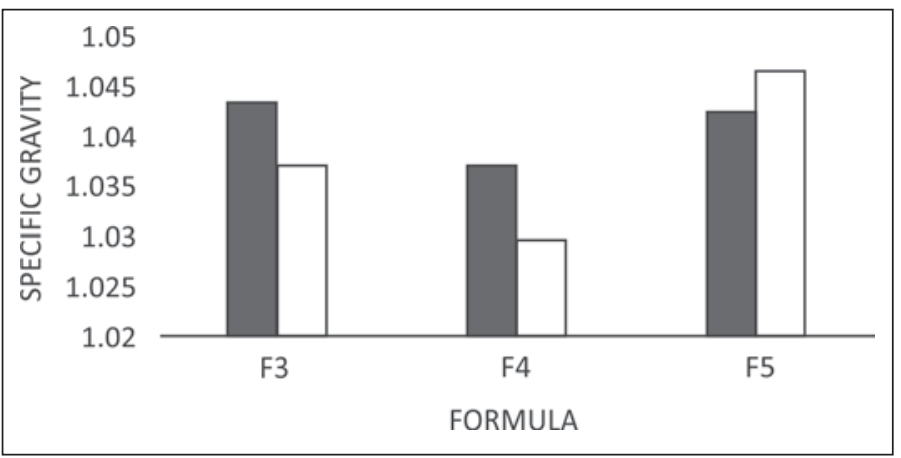

FIGURE 7. Histogram Specificity of Microemulsion Type O / W F3, F4, and $\mathbf{F 5}$

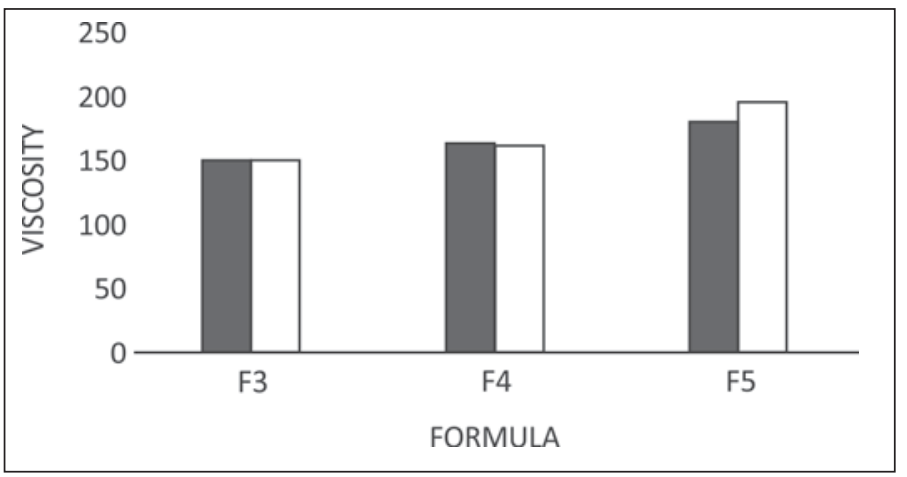

FIGURE 8. Histogram Viscosity of Microemulsion Type O / W F3, F4, and $\mathrm{F5}$ 


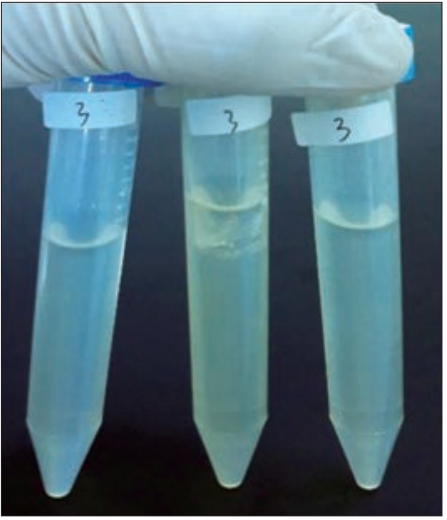

FIGURE 9. Tampilan Fisik Mikroemulsi Tipe O/W F3, F4, dan F5 setelah di uji Sentrifugasi

solution will tend to shrink and the oil phase tends to freeze at low temperatures until the particles tends to shrink and the oil phase tends to freeze until particles tend to join together and the bonds become tighter as a result viscosity increases. This phenomenon shows with changes to $\mathrm{F} 3$ and $\mathrm{F} 5$ who experienced turbidity during the storage temperature of $4^{\circ} \mathrm{C}$ first cycle.

The physical stability test continues which is centrifugation test purpose to know the gravity effect on stability of microemulsion preparation. The preparation is put into a centrifuge and then rotated at a speed of 3,500 rpm while 15 minutes. The good results are obtained where the preparation is no separation before or after the cycling test.

\section{CONCLUSIONS}

Based on the analysis that conducted, it can be conclude that

Phase in Centrifugation. Acta Pharm Indones. 2011.

7. Anggraeni Y. Formulation and Physical Evaluation of Microemulsion Extract of Japanese Taro Bulbs (Colocasia esculenta (L.) Schott var antiquorum) as Anti-Aging. Universitas Islam Negeri Hidayatullah; 2015.

8. Jufri M, Anwar E, Utami PM. Stability Test Of Microemulsi Availability Using Pati Hydrolysates (De 35-40) As Stabilizer. Maj IImu Kefarmasian. 2012;3(1).

9. Callender SP, Mathews JA, Kobernyk K, Wettig SD. Microemulsion utility in pharmaceuticals: Implications for multidrug delivery. International Journal of Pharmaceutics. 2017.

10. Thakkar H, Nangesh J, Parmar M, Patel D. Formulation and characterization of lipid-based drug delivery system of raloxifene-microemulsion and selfmicroemulsifying drug delivery system. J Pharm Bioallied Sci. 2011.

11. Fanun M. Colloids in drug delivery. Colloids in Drug Delivery. 2016.

12. Pessoa RS, França EL, Ribeiro EB, Lanes PKD, Chaud NGA, Moraes LCA, et al. Microemulsion of babassu oil as a natural the comparison of vegetable oil ratios and surfactant gives the significant influenced on physical characteristics of alpha arbutin microemulsion including the droplet size, polydispersity index, zeta potential, $\mathrm{pH}$ and viscosity and remain stable after centrifugation testing. It obtained the significant differences to the droplet size with the consecutive value $0.013 \mu \mathrm{m}$; $0.023 \mu \mathrm{m} ; 0.027 \mu \mathrm{m}$, consecutive polydispersion index is 0.119 ; $0.191 ; 0.276$, the consecutive zeta potential -2.79 mV; $1.06 \mathrm{mV}$; $-3.10 \mathrm{mV}$, consecutive $\mathrm{pH}$ value is $5.18 ; 5.21 ; 5.25$, and consecutive viscosity 150.3 cps; 161.6 cps; $196.3 \mathrm{cps}$. The result that obtained shows that microemulsion preparations are not stable during the storage process.

Conflict of interest: none declared Financial support: none declared

product to improve human immune system function. Drug Des Devel Ther. 2014.

13. Swarbrick J. Encyclopedia of Pharmaceutical Technology. Encyclopedia of Pharmaceutical Technology. 2013.

14. Chair WFB, Belsito D, Hill RA, Klaassen CD. Safety Assessment of PEGylated Alkyl Glycerides as Used in Cosmetics. Cosmetic Ingredient Review. 2015.

15. Ziani K, Fang Y, McClements DJ. Fabrication and stability of colloidal delivery systems for flavor oils: Effect of composition and storage conditions. Food Res Int. 2012.

16. Ariviani S, Anggrahini S, Naruki S, Raharjo S. Characterization and chemical stability evaluation of $\beta$-carotene microemulsions prepared by spontaneous emulsification method using VCO and palm oil as oil phase. Int Food Res J. 2015.

17. Malvern Zetasizer Nano Series Performance, Simplicity, Versatility, 2014.

18. Fitriani EW, Imelda E, Kornelis C, Avanti C. Karakterisasi dan Stabilitas Fisik Mikroemulsi Tipe A/M Dengan Berbagai Fase Minyak. Pharm Sc Res. 2016;3.

19. Iradhati $\mathrm{AH}$, Jufri M. Formulation and physical stability test of griseofulvin microemulsion gel. Int J Appl Pharm. 2017. 
20. Sinko PJ, Singh Y. Martin's physical pharmacy and pharmaceutical sciences: Physical chemical and biopharmaceutical principles in the pharmaceutical sciences: Sixth edition, 2011.

21. Sabale V, Vora S. Formulation and evaluation of microemulsion-based hydrogel for topical delivery. Int J Pharm Investig. 2012.

22. Bratovcic A, Nazdrajic S, Odobasic A, Sestan I. The Influence of Type of Surfactant on Physicochemical Properties of Liquid Soap. Int J Mater Chem. 2018.

23. Tang $M$, Suendo V. Pengaruh Penambahan Pelarut Organik Terhadap Tegangan Permukaan Larutan Sabun. In: Prosiding Simposium Nasional Inovasi Pembelajaran dan Sains 2011. Bandung; 2011.

24. Mohajeri E, Noudeh GD. Effect of temperature on the critical micelle concentration and micellization thermodynamic of non-ionic surfactants: Polyoxyethylene sorbitan fatty acid esters. E-Journal Chem. 2012;

25. Yenilmez E. Desloratadine-Eudragit ${ }^{\circledR}$ RS100 Nanoparticles: Formulation and Characterization. Turkish J. Pharm. Sci., (2017).

26. Nugraheni RW. Application of Experimental Design in Optimization Of Tea Tree Oil Microemulsion Formula. J Herbal, Clin Pharm Sci. 2019.

27. Patel N, Baby B, Ramesh K, Rao P, Rajarajan S. Preparation and in-vitro evaluation of micro emulsion of anti-hypertensive drug: Valsartan. Int J Pharm Sci Res. 2012;

28. Honary S, Zahir F. Effect of Zeta Potential on the Properties of Nano-Drug Delivery Systems - A Review (Part 1). Trop J Pharm Res. 2013.

29. Khan BA, Akhtar N, Khan HMS, Waseem K, Mahmood T, Rasul A, et al. Basics of pharmaceutical emulsions: A review. African Journal of Pharmacy and Pharmacology. 2011.

30. Bernauer U, Chaudhry Q, Dusinska M, Lilienblum W, Platzek T, van Benthem J, et al. Opinion of the Scientific Committee on Consumer safety (SCCS) - Revision of the opinion on the safety of the use of titanium dioxide, nano form, in cosmetic products. Regulatory Toxicology and Pharmacology. 2015.

31. Niratker CR, Preeti, Malti. Antimicrobial activity of leaf extract of Morus indica (Mulberry) from Chhattisgarh. Asian J Plant Sci Res. 2015;5(1):28-31.

32. Jufri M, Binu A, Rahmawati J. Gameksan Formulation Of Microemulsion. Pharmaceutical Sciences and Research 2012;1(3):160-174. 